ISSN 0103-5150

Fisioter. Mov., Curitiba, v. 28, n. 1, p. 97-106, Jan./Mar. 2015

Licenciado sob uma Licença Creative Commons

DOI: http://dx.doi.org.10.1590/0103-5150.028.001.A010

\title{
Use of audiovisual media for education and self-management of patients with Chronic Obstructive Pulmonary Disease - COPD
}

\author{
Utilização de material audiovisual para educação e automanejo \\ de pacientes com Doença Pulmonar Obstrutiva Crônica - DPOC
}

Janaína Schäfer, Lisiane Lisboa Carvalho, Natacha Angélica da Fonseca Miranda, Isabel Pommerehn Vitiello, Dulciane Nunes Paiva, Andréa Lúcia Gonçalves da Silva*

Universidade de Santa Cruz do Sul (UNISC), Santa Cruz do Sul, RS, Brazil

\section{Abstract}

Introduction: Chronic Obstructive Pulmonary Disease (COPD) is considered a disease with high morbidity and mortality, even though it is a preventable and treatable disease. Objective: To assess the effectiveness of an audiovisual educational material about the knowledge and self-management in COPD. Methods: Quasiexperimental design and convenience sample was composed of COPD patients of Pulmonary Rehabilitation (PR) $(n=42)$, in advanced stage of the disease, adults of both genders, and with low education. All subjects answered a specific questionnaire before and post-education audiovisual session, to assess their acquired knowledge about COPD. Results: Positive results were obtained in the topics: COPD and its consequences, first symptom identified when the disease is aggravated and physical exercise practice. Regarding the

\footnotetext{
* JS: Grad., e-mail: janaschafer1@yahoo.com.br LLC: MSc, e-mail: lisianecarvalho@unisc.br NAFM: Grad., e-mail: natacha@mx2.unisc.br IPV: MSc, e-mail: isabelv@unisc.br DNP: PhD, e-mail: dulciane@unisc.br ALGS: PhD, e-mail: andreag@unisc.br
} 
second and third symptoms, it was observed that the education session did not improve this learning, as well as the decision facing the worsening of COPD. Conclusion: COPD patients showed reasonable knowledge about the disease, its implications and symptomatology. Important aspects should be emphasized, such as identification of exacerbations of COPD and decision facing this exacerbation.

Keywords: COPD. Self-management. Education.

\section{Resumo}

Introdução: A Doença Pulmonar Obstrutiva Crônica (DPOC) é considerada uma doença de alta morbidade e mortalidade, mesmo sendo tratável e havendo a possibilidade de prevenção. Objetivo: O objetivo foi avaliar a efetividade de um material educativo audiovisual sobre conhecimento e automanejo da doença em portadores de Doença Pulmonar Obstrutiva Crônica (DPOC). Métodos: Estudo de delineamento quase-experimental e amostragem de conveniência, composto por 42 portadores de DPOC do programa de Reabilitação Pulmonar (RP), com doença em estágio avançado, em idade adulta, de ambos os sexos e baixa escolaridade. Todos os sujeitos foram submetidos à aplicação de um questionário específico pré e pós-sessões de educação com material audiovisual, para avaliar o conhecimento adquirido sobre o DPOC. Resultados: Foram obtidos resultados positivos nos temas: doenças que compreendem a DPOC e suas consequências, primeiro sintoma identificado quando a doença está agravada e prática de exercício físico. Quanto ao segundo e terceiro sintomas, observou-se que a sessão de educação não aperfeiçoou esse aprendizado, assim como a tomada de decisão diante do agravamento da DPOC. Conclusão: Os portadores de DPOC têm razoável conhecimento da doença, de suas implicações e sintomatologia. Aspectos importantes devem ser enfatizados, como identificação da exacerbação da DPOC e tomadas de decisão diante dessa exacerbação.

Palavras-chave: DPOC. Automanejo. Educação.

\section{Introduction}

Chronic Obstructive Pulmonary Disease (COPD) is considered a disease with high mortality, even though it is preventable and treatable $(1,2)$. It is characterized by non-reversible or partially reversible airflow limitation resulting from an abnormal inflammatory response to inhaled toxic particles and associated with comorbidities, which manifests through several symptoms, among which are dyspnea and exercise capacity limitation $(3,4)$. Additionally, emotional problems such as depression, anxiety and social isolation are also observed (2).

The gradual deterioration typical of the disease may be intermingled with periods of acute worsening of symptoms of dyspnea, cough, wheezing, sputum production and recurrent respiratory infections (5, 2 ). Exacerbation crises have shown to be dramatically damaging to the sense of well-being in COPD patients, affecting their quality of life (6).

Early recognition and prompt treatment of exacerbations improve the clinical outcome and reduce the risk of hospitalization $(7,8)$. Studies have shown that educational programs on COPD result in quality of life improvement, reduce morbidity and significantly decrease healthcare costs $(3,9,10)$. This program includes general information on COPD, medications, inhalation techniques, smoking cessation counseling, recommendations for vaccines such as influenza and pneumonia and encouraging regular practice of physical exercise (11). The interventions involving the collaboration of patients in acquiring and practicing the skills that are necessary to improve daily living control the disease and their well-being, thus requiring a change in behavior by these patients (12).

There is evidence that a plan of action for COPD patients with limited education fails in recognizing and responding to disease exacerbation. Education for selfmanagement is also limited due to the implications of passive transfer of knowledge (13). However, the benefits of educational programs are still little known regarding the reduction in hospitalizations and visits to emergency health services $(8,14)$. 
We hypothesized that COPD patients educated on their disease with specific audiovisual tools have greater awareness of COPD and make correct decisions when facing exacerbation crises. Based on the above, this study aimed to evaluate the impact of using audiovisual educational materials on disease knowledge and self-management in COPD patients.

\section{Methods}

The present study had a quasi-experimental design with a convenience sample and was carried out together with the Cardiopulmonary Rehabilitation Program at Hospital Santa Cruz, Santa Cruz do Sul, RS, Brazil. It was appropriately approved by the Research Ethics Committee by University of Santa Cruz do Sul, under protocol number 178283. The data collection took place after authorization and signing of the informed consent form by the study subjects, in order to formalize their decision regarding the use of a specific education protocol for COPD self-management.

The study included COPD patients with a confirmed diagnosis of the disease through lung function tests (spirometry), regardless of the disease stage, of both gender and without age limit. Subjects with cognitive deficits, mental confusion, disease exacerbation and dyspnea crises, as well as also patients with COPD who were experiencing exacerbation of comorbidities associated with COPD were excluded from the sample.

All study participants underwent thorough clinical evaluation through a standard questionnaire for sociodemographic and clinical data collection. The knowledge of the subjects regarding COPD and its treatment were tested using a specific questionnaire, consisting of multiple-choice questions and some open questions (15). The educational session for COPD, lasting seven minutes, was carried out using iconographic educational material on COPD (3), containing information that was succinct and appropriate to the cultural level of the patients, on the following contents: definition of COPD, risk factors, clinical features, symptoms, disease treatment, physical exercise, and disease exacerbation.

The research was performed in two steps: $1^{\text {st }}$ step (Q1) - when the questionnaire was applied, and after that, an education session was carried out using audiovisual material and then the questionnaire was reapplied (Q2); $2^{\text {nd }}$ step (Q3) - carried out two weeks after the $1^{\text {st }}$ step, by reapplying the questionnaire (Figure 1). All steps, as well as audiovisual educational session were held individually in a closed room, with the examiner sitting next to the patient. At this step, the patients were asked to manifest through discussions, asking questions and clarifying any doubts. Data were entered and analyzed using the SPSS $^{\text {tw }}$ Statistical Program 20.0.

\section{Results}

After the selection of subjects according to the methodology defined for the study, 43 COPD patients were included in this study. During the study, one patient was lost to follow-up, totaling 42 patients whose clinical and sociodemographic characteristics are described in Table 1.

There was equivalence between genders, with predominance of Caucasians (81\%), advanced adult age and high prevalence of smoking. Regarding the body mass index (BMI), there were subjects with normal weight (45\%), as well as malnourished (29\%) and obese individuals (26\%). Patients' low educational level on COPD was noteworthy, in which $62 \%$ of the sample had not finished Elementary School. Lung function test results classified the COPD patients as having severe disease (48\% severe and $26 \%$ very severe diseases) (Table 1 ).

Among the most frequent comorbidities were systemic arterial hypertension ( $\mathrm{SAH}$ ), diabetes mellitus and heart disease. Due to the presence of comorbidities, the current use of medications, in addition to the prescribed COPD medications, was observed, which included corticosteroids, bronchodilators, oxygen therapy and antihypertensive drugs. The time of treatment through pulmonary rehabilitation (PR) was also evaluated and as it can be observed, it varied widely, with $57 \%$ of the sample having between 1 and 2 years of PR.

The following figures represent the statements of the patients when asked the questions posed by questionnaires Q1, Q2 and Q3, as well as the maintenance of correct assertions between questionnaires (Q1-Q2, Q2-Q3). Figures 2A and 2B display the responses about the diseases that comprise COPD and the possible consequences of this pathology, respectively. One can observe that after the presentation of audiovisual material for both questions, there was an increase in the correct answers ( 3 and 4 patients, 
respectively), in view of the fact that Pulmonary Emphysema and Chronic Bronchitis are diseases that characterize COPD and its possible consequences is shortness of breath, difficulty to move, social isolation and depression. It can also be observed that after the education session the subjects maintained their correct answers.

Patients' responses regarding the three most common symptoms that precede a COPD exacerbation crisis are shown in Figures 3A, 3B, and 3C. Regarding the first symptom a COPD patient identifies when the disease is exacerbated, $100 \%$ of patients responded correctly, i.e., "increased shortness of breath". As for the second (e.g. "cough") and third symptoms (e.g., "increased production of phlegm") it was observed that the educational session did not improve this knowledge, and thus the responses varied throughout the study, including in the same patients.

About on disease exacerbation (Figure 4) the patients' responses were negative, even after the audiovisual presentation, i.e., they seek hospital emergency care even before performing self-mediation for exacerbation, according to the prescribed drugs or contacting their physicians. Patients' responses regarding the unconventional treatment of $\mathrm{PR}$, it is observed that all patients in the study responded positively about PR.

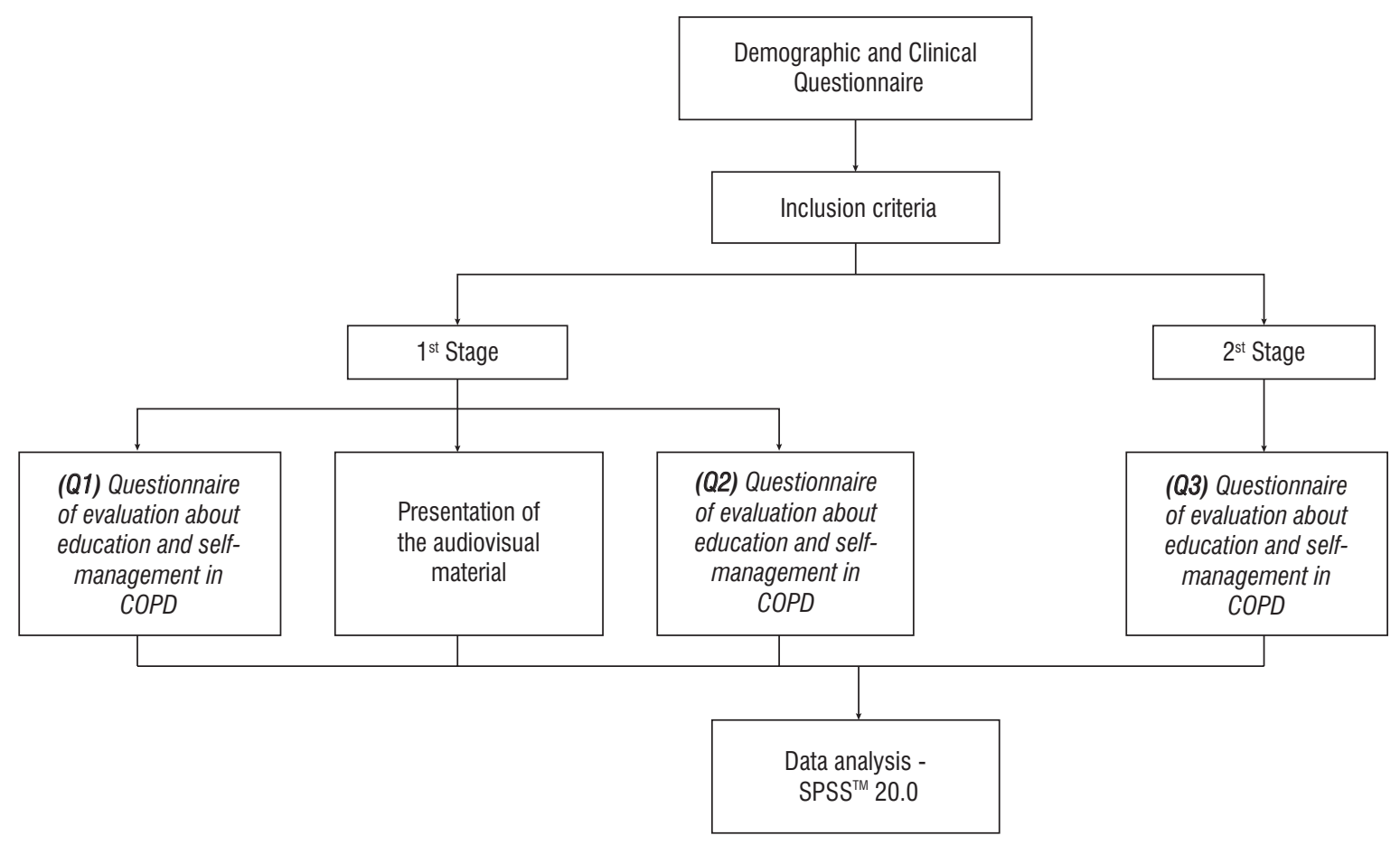

Figure 1 - Flow diagram to methodological stages of the research

Table 1 - Clinical characteristics and education of patients with COPD, staging of COPD, comorbidities and treatments

(To be continued)

\begin{tabular}{lc}
\hline Characteristics & COPD $\mathbf{n}=42$ \\
\hline Gender Female $\mathbf{n}(\%)$ & $22(52)$ \\
White Ethnicity $\mathbf{n}(\%)$ & $34(81)$ \\
Age (years) & a
\end{tabular}


Table 1 - Clinical characteristics and education of patients with COPD, staging of COPD, comorbidities and treatments

(Conclusion)

\begin{tabular}{|c|c|}
\hline Characteristics & COPD $n=42$ \\
\hline BMI $(\mathrm{kg} / \mathrm{m} 2)^{\mathrm{a}}$ & $24.95 \pm 5.63$ \\
\hline \multicolumn{2}{|l|}{ Level of education n (\%) } \\
\hline lliterate & $3(7)$ \\
\hline Incomplete Elementary School & $26(62)$ \\
\hline Elementary School Full & $7(17)$ \\
\hline Junior High School & $5(12)$ \\
\hline Incomplete Higher Education & $1(2)$ \\
\hline \multicolumn{2}{|l|}{ Smoking Status n (\%) } \\
\hline Never/Former smoker/Smoker & $2(5) / 34(81) / 6(14)$ \\
\hline Cigarettes-year ${ }^{b}$ & $7300(730-25550)$ \\
\hline Smoking $>30$ years & $32(76)$ \\
\hline \multicolumn{2}{|l|}{ Staging of $\mathrm{COPD}^{\mathrm{c}} \mathrm{n}(\%)$} \\
\hline Mild & $1(2)$ \\
\hline Moderate & $10(24)$ \\
\hline Severe & $20(48)$ \\
\hline Very Severe & $11(26)$ \\
\hline Comorbidities n (\%) & $29(69)$ \\
\hline SAH & $20(48)$ \\
\hline Diabetes & $7(17)$ \\
\hline Cardiopathy & $6(14)$ \\
\hline \multicolumn{2}{|l|}{ Medications n (\%) } \\
\hline Bronchodilator & $42(100)$ \\
\hline Corticosteroid & $25(59)$ \\
\hline Antihypertensive & $19(45)$ \\
\hline Oxygen Therapy & $6(14)$ \\
\hline \multicolumn{2}{|l|}{ PR Time n (\%) } \\
\hline Middle year & $4(9)$ \\
\hline One year & $14(33)$ \\
\hline Two years & $10(24)$ \\
\hline Three years & $2(5)$ \\
\hline More than three years & $12(29)$ \\
\hline
\end{tabular}

Notes: ${ }^{a}$ Data are presented with mean $\pm \mathrm{SD}$; ${ }^{\mathrm{b}}$ Median (minimum-maximum); ${ }^{\mathrm{c}}$ Patients were staged according to GOLD (2014) through function test pulmonary; $\mathrm{n}=$ sample number; $(\%)=$ frequency; $\mathrm{BMI}=$ Body Mass Index; $\mathrm{SAH}=$ Systemic Arterial Hypertension; $\mathrm{PR}=$ Pulmonary Rehabilitation. 
A. What are the diseases that characterize COPD?

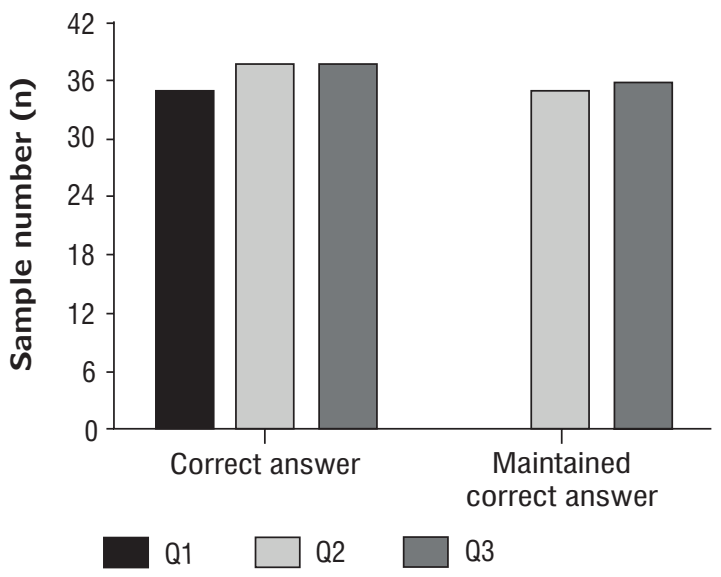

B. What are the possible consequences of COPD?

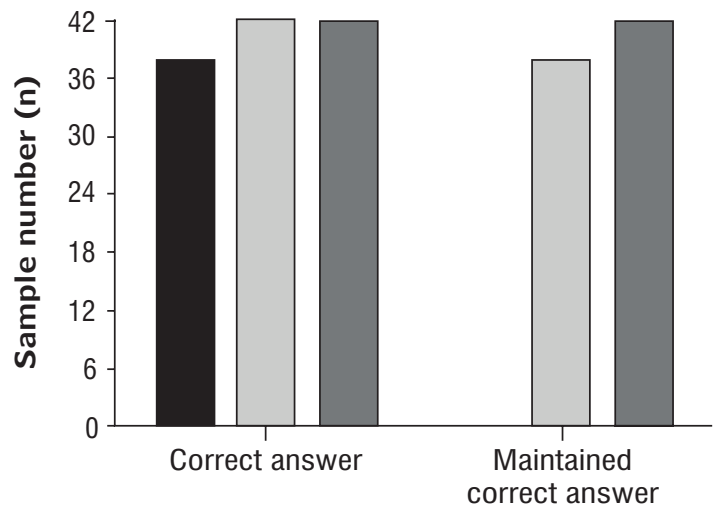

Q

Q2

Q3

Figure 2 - Patients' responses about the diseases that comprise COPD and the possible consequences of this pathology, respectively

Note: A) What are the diseases that characterize COPD? Correct answer: Pulmonary Emphysema or Chronic Bronchitis. B) What are the possible consequences of COPD? Correct answer: Shortness of breath or difficulty moving or social isolation or depression. Q1 = Questionnaire applied before the education session. Q2 = Questionnaire applied after the education session. Q3 = Questionnaire applied 2 weeks after the $1^{\text {st }}$ step (Q1).

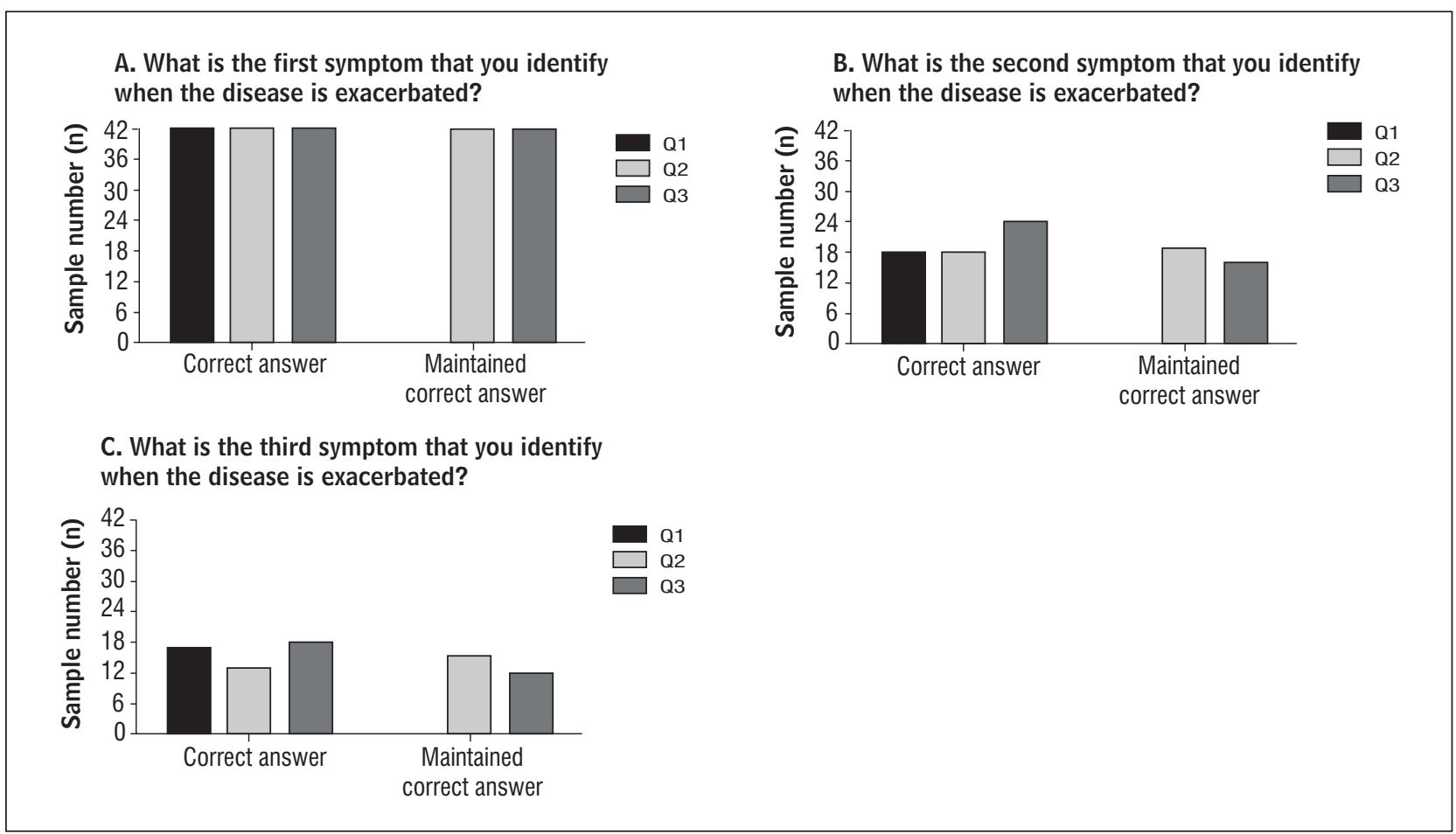

Figure 3 - Patients' responses regarding the three most common symptoms that precede a COPD exacerbation crisis Note: A) What is the first symptom that you identify when the disease is exacerbated? Correct answer: Increased breathlessness. B) What is the second symptom that you identify when the disease is exacerbated? Correct answer: Cough. C) What is the third symptom that you identify when the disease is exacerbated? Correct answer: Increased sputum secretion. Q1 = Questionnaire applied before the education session. Q2 = Questionnaire applied after the education session. Q3 = Questionnaire applied 2 weeks after the $1^{\text {st }}$ step (Q1). 


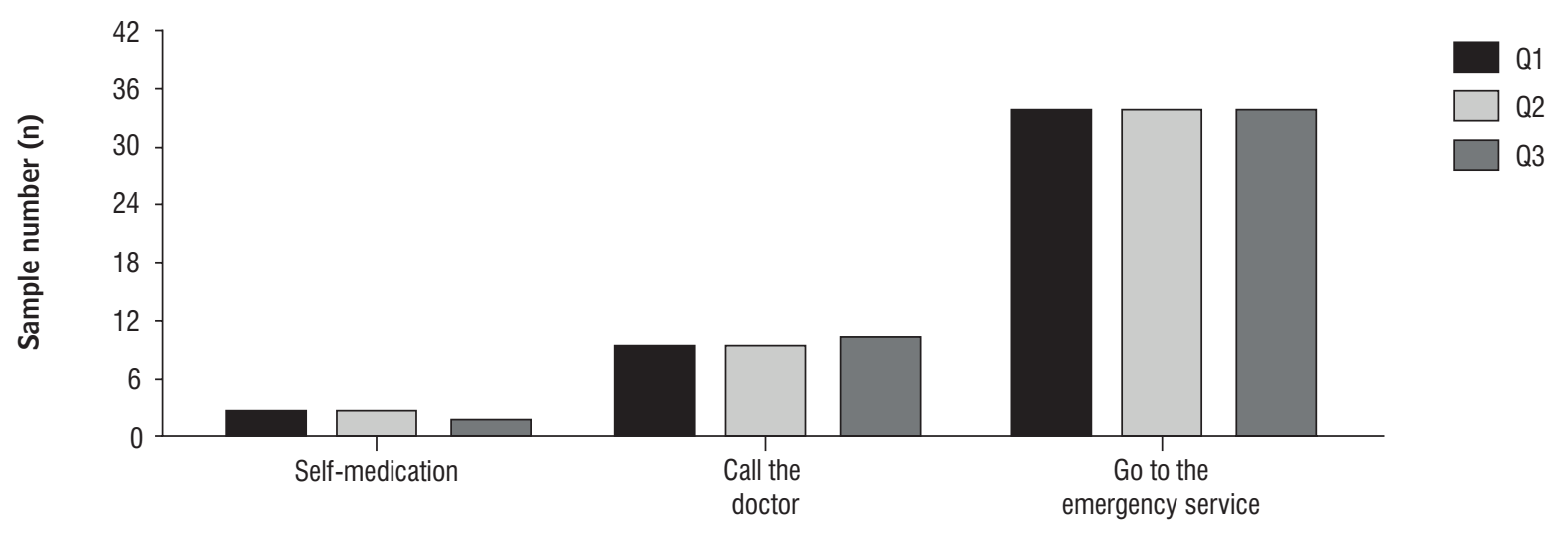

Figure 4 - What is the first step to take when you identify the worsening of the disease?

Note: Correct answer: Self-medication or call the doctor or go to the emergency service. Q1 = Questionnaire applied before of the education session. Q2 = Questionnaire applied after the education session. Q3 = Questionnaire applied 2 weeks after the $1^{\text {st }}$ step (Q1).

\section{Discussion}

The clinical characteristics observed in our study and described in Table 1 is in accordance with the literature (16-25). COPD was originally known to be a disease with higher prevalence in men and can be associated with comorbidities (16). The prevalence of Caucasian ethnicity and smoking in this study was similar to that described in the literature (3). As seen in our study, studies have reported that the frequency of smoking is also related to low educational level (17), which in turn correlates with poorer quality of life (18). It is believed that patients with a lower educational level have less fatigue and more energy to perform daily activities.

Regarding disease staging, our results are not surprising, as COPD patients are referred to PR when the disease staging is moderate, as recommended by GOLD (3). Despite the degree of disease severity exhibited by this study subjects, their nutritional status, which is one of the predictors of mortality in this population, was within the appropriate parameters in most cases, i.e., normal weight, according to the Nutrition Screening Initiative, the American Academy of Family Physicians and the American Dietetic Association (19-21).

\section{Summary of main findings}

Concerning the educational process of COPD patients, this study demonstrated an adequate level of knowledge by the subjects regarding the definition of COPD, the group of diseases that comprises COPD, disease consequences (e.g., shortness of breath, difficulty moving, social isolation, depression) and the first symptom before a crisis exacerbation, even before the educational session (Figures 2A, 2B and 3A).

According to the American Thoracic Society (25, p. 14), Pulmonary Rehabilitation is defined as a

comprehensive intervention based on a thorough patient assessment followed by patient-tailored therapies, which include, but are not limited to, exercise training, education, and behavior change, designed to improve the physical and psychological condition of people with chronic respiratory disease and to promote the long-term adherence of health-enhancing behaviors.

The COPD treatment program includes four components: assess and monitor the disease, risk factor reduction; stable COPD management; conduct during exacerbations $(3,4,22,23)$.

During the course of a chronic disease such as COPD, the patient and family are in a constant qualified learning process, in which new behaviors are required for adequate disease management (26). The patient and family must learn to engage in activities that promote health through self-management and to prevent complications, ensuring the participation of patients in the daily routine (26). This can be seen 
in this study when COPD patients were asked about the benefits of PR.

Studies have shown that self-management is the most important item of educational programs for patients, disclosing quality of life improvement, reduced morbidity and significant decrease in healthcare costs $(3,9,10)$. Adequate time and follow-up are essential to increase its effectiveness and change patient behavior, which in turn leads to better disease control and may reduce the likelihood of hospitalization (26).

The idea of self-management is to teach patients the necessary skills to carry out medical regimens specific to COPD, a guide to health behavior changes and provide emotional support for patients to manage their disease $(14,27)$. The range of information to be worked on, to achieve the goal of self-management in patient behavior change, requires professionals skilled in educational methodology capable of managing an effective action plan for self-management. Most action plans include early detection, medication start and adjustment in the event of COPD exacerbation $(13,28)$. Case management promotes continuity, communication, collaboration between the patient, family, physicians and health care providers $(14,27)$.

The method chosen for patient education differs greatly among the many studies, but considering the consistency of results, it is possible to state that access to information is the determining factor, stressing the variation regarding the number, regularity and method used in the sessions, number of participants (individual/group) and the characteristics of the trainers (doctors/physiotherapists/nurses) (15). In this respect, our study shows that the learning process in COPD patients is often carried out through their own experiences and their involvement in the PR programs. This fact can be observed when subjects are asked about the order of symptom appearance that comprises COPD exacerbation.

"Increased breathlessness" was the correct and unanimous answer among the patients; however, for the second and third symptoms, only a portion of patients responded assertively out of the group of offered answers, even after an educational session with audiovisual material (Figures 3A, 3B and 3C). We believe this fact was due to different personal experiences when facing a COPD exacerbation crisis. The same negative event was observed for decisionmaking in the presence of COPD exacerbation.

Education is considered an important component of pulmonary rehabilitation and among the potential benefits of education are: active participation in health care area, increased coping skills, a better understanding of the physical and psychological alterations of chronic disease, more skills in self-management and better adherence to the treatment plan (25).

Considering the results, it is clear that COPD patients attending a Pulmonary Rehabilitation Program at Hospital Santa Cruz have adequate knowledge about the disease, its implications and symptoms. Important aspects, such as COPD exacerbation identification and decision making in the presence of this exacerbation should be emphasized in this group of patients, so that demand for emergency care be actually necessary. The participation of these individuals from pulmonary rehabilitation programs, when well-structured, organized and directed, might be able to educate patients with COPD through their personal experiences.

\section{Limitations of this study}

There are aspects that should be improved in the COPD education process, here performed individually and with audiovisual tools, as it did not seem to add changes to the educational process of these subjects, unlike other studies reported in the literature.

\section{The implications for future research or clinical practice}

This study may contribute to the discussion about what should be offered to patients with COPD. Future researches should focus on the cognitive impairment of COPD patients, on neuropsychological tests, and their implications for education. Therefore, it is necessary to further evaluate the effects of long-term patient education programs on morbidity, quality of life, mortality and treatment costs.

\section{Acknowledgements}

We thank the subjects who participated in this study, the CCGS' physiotherapy team and the Santa Cruz Hospital. 


\section{References}

1. Mendes FAR, Moreno IL, Durand MT, Pastre CM, Ramos EMC, Vanderlei LCM. Analysis of cardiovascular system responses to forced vital capacity in COPD. Rev Bras Fisioter. 2011;15(2):102-8. doi: 10.1590/ S1413-35552011000200004.

2. Langer D, Probst VS, Pitta F, Burtin C, Hendriks E, Schans CPVD, et al. Clinical Practice Guideline for physical therapy in patients with Chronic Obstructive Pulmonary Disease (COPD) - Portuguese version. Rev Bras Fisioter. 2009;13(3):183-204. doi: 10.1590/ S1413-35552009005000034.

3. Global Initiative for Chronic Obstructive Lung Disease - GOLD [Internet]. Global Strategy for the Diagnoses, management, and prevention of Chronic Obstructive Pulmonary Disease. 2014 [cited 2014, July 10]. Available from: http://www.goldcopd.org/ uploads/user/files/GOLD_Report_2014_Jan23.pdf.

4. Wehrmeister FC, Knorst M, Jardim JR, Macedo SEC, Noal RB, Martínez-Mesa J, et al. Programas de reabilitação pulmonar em pacientes com DPOC. J Bras Pneumol. 2011;37(4):544-55. doi: 10.1590/ S1806- 37132011000400017.

5. Pincelli MP, Grumann ACB, Fernandes C, Cavalheiro AGC, Haussen DAP, Maia IS. Characteristics of COPD patients admitted to the ICU of a referral hospital for respiratory diseases in Brazil. J Bras Pneumol. 2011;37(2):217-22. doi: 10.1590/ S1806-37132011000200012.

6. Anzueto A. Impact of exacerbations on COPD. Eur Respir Rev. 2010;19(116):113-8. doi: 10.1183/ 09059180.00002610 .

7. Rodríguez-Roisin R. COPD exacerbations 5: management. Thorax. 2006;61(6):535-44.

8. Gadoury MA, Schwartzman K, Rouleau M, Maltais F, Julien M, Beaupré A, et al. Self-management reduces both short- and long-term hospitalisation in COPD. Eur Respir J. 2005;26(5):853-7. doi: 10.1183/ 09031936.05.00093204.

9. Bourbeau J, Collet J-P, Schwartzman K, Ducruet T, Nault D, Bradley C. Economic benefits of self-management education in COPD. Chest. 2006;130(6):1704-11. doi: 10.1378/chest.130.6.1704.
10. Worth H, Dhein Y. Does patient education modify behaviour in the management of COPD? Patient Educ Couns. 2004;52(3):267-70.

11. Rice KL, Dewan N, Bloofield HE, Grill J, Schult TM, Nelson DB, et al. Disease management program for chronic obstructive pulmonary disease: a randomized controlled trial. Am J Respir Crit Care Med. 2010;182(7):890-6. doi: org/10.1164/rccm. 200910-15790C.

12. Bourbeau J, van der Palen J. Promoting effective self-management programmes to improve COPD. Eur Respir J. 2009;33(3):461-3. doi: 10.1183/0903 1936.00001309.

13. National Institute for Health and Clinical Excellence NICE. Chronic obstructive pulmonary disease: Management of Chronic Obstructive Pulmonary Disease in Adults in Primary and Secondary Care. London: Royal College of Physicians (UK); 2010.

14. Bourbeau J, Julien M, Maltais F, Rouleau M, Beaupre A, Begin R, et al. Reduction of hospital utilization in patients with chronic obstructive pulmonary disease: a disease-specific self-management intervention. Arch Intern Med. 2003;163(5):585-91. doi: 10.1001/ archinte.163.5.585.

15. van Zeller M, Vaz AP, Soares Pires F, Neves I, Drummond M, Carvalho AM, et al. Efficacy evaluation of educational sessions for patients with asthma and COPD. Rev Port Pneumol. 2012;18(1):29-33. doi: 10.1016/j.rppneu.2011.07.005.

16. Nyberg A, Lindström B, Wadell K. Assessing the effect of high-repetitive single limb exercises (HRSLE) on exercise capacity and quality of life in patients with chronic obstructive pulmonary disease (COPD): study protocol for randomized controlled trial. Trials. 2012;13(1):114. doi: 10.1186/1745-6215-13-114.

17. Silva MS. Qualidade de vida relacionada à saúde de pacientes com doença pulmonar obstrutiva crônica [dissertação]. São Paulo: Universidade de São Paulo; 2011.

18. Cedano S, Belasco AGS, Traldi F, Machado MCLO, Bettencourt ARC. Influence that sociodemographic variables, clinical characteristics, and level of dependence have on quality of life in COPD patients on long-term home oxygen therapy. J Bras Pneumol. 2012;38(3):331-8. doi: 10.1590/S1806-37132012000300008. 
19. American Academy of Family Physicians; American Dietetic Association. A physician's guide to nutrition in chronic disease management for older adults. Washington, DC: Nutrition Screening Initiative, 2002.

20. Fernandes AC, Bezerra OMPA. Nutrition therapy for chronic obstructive pulmonary disease and related nutritional complications. J Bras Pneumol. 2006;32(5):46171. doi: 10.1590/ S1806-37132006000500014.

21. Pitta F, Probst VS, Langer D, Troosters T, Gosselink R. A practical guide for physical therapy treatment of patients with Chronic Obstructive Pulmonary Disease (COPD): combining scientific evidence and clinical practice. Rev Bras Fisioter. 2009;13(3):5-6. doi: 10.1590/S1413-35552009000300001.

22. Fernandes ABS. Reabilitação respiratória em DPOC - a importância da abordagem fisioterapêutica. Pulmão RJ. 2009;1(1):71-8.

23. Chang AT, Haines T, Jackson C, Yang I, Nitz J, Low Choy N, et al. Rationale and design of the PRSM study: pulmonary rehabilitation or self-management for chronic obstructive pulmonary disease (COPD), what is the best approach? Contemp Clin Trials. 2008;29(5):796800. doi: 10.1016/j.cct.2008.04.004.

24. Valk P, Monninkhof E, Palen J, Zielhuis G, Herwaarden C. Management of stable COPD. Patient Educ Couns. 2004;52(3):225-9. doi: 10.1016/ S0738- 3991(03)00095-8.
25. Spruit MA, Singh SJ, Garvey C, ZuWallack R, Nici L, Rochester C, et al. An official American Thoracic Society/European Respiratory Society statement: key concepts and advances in pulmonary rehabilitation. Am J Respir Crit Care Med. 2013;188(8):e13-64. doi: 10.1164/rccm.201309-1634ST.

26. Bourbeu J, Johnson M. New and controversial therapies for chronic obstructive pulmonary disease. Proc Am Thorac Soc. 2009;6(6):553-4. doi: 10.1513/ pats.200906-039DS.

27. Effing T, Monninkhof EM, van der Valk PD, van der Palen J, van Herwaarden CL, Partidge MR, et al. Selfmanagement education for patients with chronic obstructive pulmonary disease. Cochrane Database Syst Rev. 2007;(4):CD002990

28. Emtner M, Hedin A, Andersson M, Janson C. Impact of patient characteristics, education and knowledge on emergency room visits in patients with asthma and COPD: a descriptive and correlative study. BMC Pulm Med. 2009;9:43. doi: 10.1186/1471-2466-9-43.

Received: $12 / 03 / 2013$

Recebido: 03/12/2013

Approved: 05/18/2014 Aprovado: 18/05/2014 